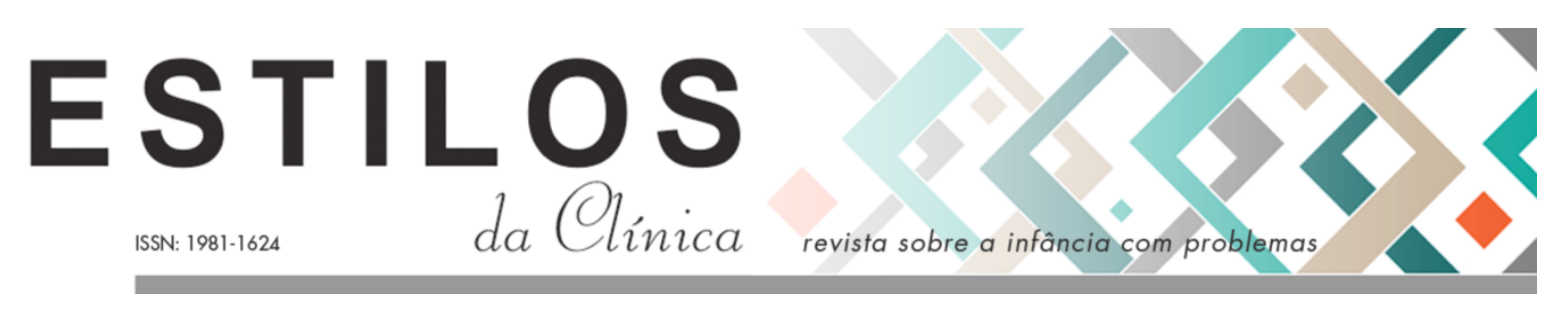

DOI: https://doi.org/10.11606/issn.1981-1624.v24i1p4-11.

\title{
Dossiê
}

\section{Escola consumada e consumida: o declínio da política na contemporaneidade e seus efeitos sobre a escola}

\author{
Douglas Emiliano Batista ${ }^{1}$
}

Resumo. Este artigo procura distinguir o dispositivo escolar que foi hegemônico na modernidade daquele que é hegemônico na contemporaneidade: enquanto o primeiro era indissociável do ressurgimento da política nos primórdios dos tempos modernos, o segundo o é do declínio da política - e da consequente ascensão da tecnoburocracia e da tecnociência - nas últimas décadas do século XX. Nesses termos, o dispositivo escolar hegemônico na contemporaneidade vem sendo consumido para melhor se consumar, o que significa que a escola admitida hoje como ideal é a que se faz onipresente (consumada) na proporção em que é também radicalmente desescolarizada (consumida). Trata-se de dessimbolizar a escola (no que concerne, por exemplo, à transferência do aluno ao professor) para adequá-la aos imperativos visados pela tecnoburocracia e pelo mercado nos termos aparentemente democráticos do gozo de uma inclusão total. Desse modo, o dispositivo escolar acaba sendo consumido e consumado na medida em que seu objetivo já não é tanto formar sujeitos e cidadãos do EstadoNação, mas conformar indivíduos e consumidores de um mundo global.

Palavras-chave: dispositivo escolar moderno; dispositivo escolar contemporâneo; declínio da política; dessimbolização da escola contemporânea.

\section{Escuela consumada y consumida: el declive de la política en la contemporaneidad y sus efectos sobre la escuela}

Resumen. Este artículo busca distinguir el dispositivo escolar que fue hegemónico en la modernidad del dispositivo escolar que es hegemónico en la contemporaneidad: el primer era indisociable del resurgimiento de la política a principios de los tiempos modernos; el segundo es indisociable del declive de la política y del consecuente ascenso de la tecnoburocracia y de la tecnociencia en las últimas décadas del siglo XX. En esas condiciones, el dispositivo escolar hegemónico en la contemporaneidad se está consumiendo para consumarse mejor, lo que significa que la escuela considerada hoy como la ideal es la que es omnipresente (consumada) en medida que es también radicalmente desescolarizada (consumida). Se trata de reducir el estofo simbólico de la escuela -en lo que concierne, por ejemplo, a la transferencia del alumno al profesor- para adecuarla a los imperativos buscados por la tecnoburocracia y por el mercado en los términos aparentemente democráticos de

1. Professor da Faculdade de Educação da Universidade de São Paulo (FE-USP), São Paulo, SP, Brasil. Coordenador e docente do Mestrado em Educação da Universidade Ibirapuera (Unib), São Paulo, SP, Brasil. E-mail:demilian@uol.com.br 
goce de una inclusión total. De ese modo, el dispositivo escolar termina siendo consumido y consumado en la medida que su objetivo ya no es más formar sujetos y ciudadanos del Estado nación, sino el de modelar individuos y consumidores de un mundo global.

Palabras clave: dispositivo escolar moderno; dispositivo escolar contemporáneo; declive de la política; declive simbólico de la escuela contemporánea.

\section{Consummate and consumed school: the decline of politics in contemporaneity and its effects on school}

Abstract. this article seeks to distinguish the school device that was hegemonic in modernity from that that is
hegemonic in contemporaneity: while the former was inseparable from the resurgence of politics in the
beginnings of modern times, the latter is inseparable from the decline of politics - and the consequent rise of
technobureaucracy and technoscience - in the last decades of the 20 th century. In these terms, the hegemonic
school device in contemporaneity has been consumed in order to be better consummated, which means that the
school admitted as the ideal today is the one that becomes omnipresent (consummated) to the extent that it is
also radically de-educated (consumed). It is about de-symbolizing the school (for instance, considering the
transference from the student to the teacher) in order to adjust it to the imperatives aimed by technobureaucracy
and the market in the apparently democratic terms of the enjoyment (jouissance) of total inclusion. Therefore,
the school device ends up being consumed and consummated insofar as its objective is not so much to form
subjects and citizens of the Nation-State, but to conform individuals and consumers of alobal world. Keywords: modern school device; contemporary school device; decline of politics; de-symbolization of contemporary school.

Abordagem do tema "A Escola: consumada ou consumida?" exige, a meu ver, que se considere uma distinção basilar. É preciso distinguir o dispositivo escolar hegemônico na contemporaneidade, que se tornou prevalente desde as últimas décadas do século XX e cuja lógica tem se acirrado ao longo do tempo, e o dispositivo escolar que foi hegemônico na modernidade, na segunda metade do século XIX e primeiras décadas do XX.

Em outras palavras, é imprescindível diferenciar, por um lado, o dispositivo escolar contemporâneo, que vem sendo consumado e consumido desde o final do século XX e, por outro, o moderno, dispositivo que foi universalizado em inúmeros países (muito embora não no Brasil) no avançado século XIX e início do $\mathrm{XX}^{2}$.

Em suma, distinguir a escola contemporânea (ou escola da modernidade tardia) e a moderna (ou Escola da República) é muito relevante pela seguinte razão: enquanto a contemporânea (con)forma primordialmente indivíduos e consumidores globais, a moderna formava primordialmente sujeitos e cidadãos do Estado-Nação, tal como se pode depreender a partir de Dufour (2005). Ou mais especificamente: a escola contemporânea é tributária, talvez sobretudo, do declínio da política e da consequente ascensão da tecnoburocracia e da tecnociência na segunda metade do século XX. Já a escola universal, aquela moderna ou republicana, foi tributária da elevação da política a uma nova dignidade no século XVIII (o século das revoluções), ou sob outra perspectiva, tal escola foi tributária até mesmo do ressurgimento da política ainda no Renascimento, como ensina Claude Lefort (1999).

Com base em tal diferenciação, eu pretendo agora abordar alguns aspectos da escola contemporânea.

2 Tal como se verá mais à frente, a consumação escolar contemporânea não se confunde com a universalização escolar moderna, e isso pelo fato de a consumação contemporânea estar embebida em tecnocracia, tecnociência e imperativos neoliberais, enquanto a universalização escolar moderna estava embebida, fundamentalmente, em espírito público. 
A meu ver, o dispositivo escolar hegemônico na contemporaneidade é consumido e consumado (ou que vem se consumando e se consumindo desde o final do século XX, como já referido). E tanto é assim que se espera hoje em dia da escola que ela seja integral, porém desconstruída (consumada e consumida). Isto é, espera-se que ela opere em regime de tempo integral, mas conquanto seja radicalmente desconstruída. Em outros termos, espera-se que a escola de hoje seja onipresente (com a ajuda da internet), mas desde que ela seja também profundamente desescolarizada (consumação e consumição). Como se observa, a escola contemporânea porta as marcas sintomático-sociais da miséria neurótica, uma vez que conjuga sem mais a onipotência da consumação e a impotência da consumição.

Eis que a escola consumida e consumada se encontra extraordinariamente idealizada, imaginarizada. E em função disso, tudo se espera hoje da escola, mas conquanto ela se converta numa antiescola. Todavia, quando tudo se espera da educação, talvez nada ou quase nada se espera da política. Nesse sentido, pode-se afirmar que a idealização da escola contemporânea talvez derive fundamentalmente da declinação da polis.

Com vistas a ilustrar essa tese, eu gostaria de analisar um pequeno excerto do artigo de Cláudia Costin (2017) que foi publicado na Folha de S.Paulo recentemente: "num país cada vez mais desesperançado", diz a autora, "a educação deveria ser o eixo de reconstrução nacional e o ponto de convergência dos esforços para transformar a realidade" (https://bit.ly/2Y4Jtxq).

Ora, esperar que a escola seja o eixo da reconstrução nacional é esperar demais do dispositivo escolar; é sobrecarregá-lo imaginariamente. Almejar que ela transforme a realidade é esperar demais da educação e de menos da política, uma vez que é da política mesmo quando declinada - que se pode ensejar transformação ou conservação legítima do status quo.

A meu ver, o ponto de vista de Costin acena, tal como é hoje hegemônico, para o voto psiquicamente incestuoso de fazer por meio educação e junto às crianças o que não se faz por meio da política e junto aos adultos. E vale dizer que me parece de fato incestuoso que os adultos (cidadãos formados) façam política com as crianças (cidadãos em formação ou candidatos a cidadãos). Entretanto, é justamente quando a República declina que então muitos adultos passam a acreditar em uma República das crianças na escola. É justamente quando o mundo público se degrada que muitos adultos passam a acreditar que há um mundo público das crianças na escola, tal como já alertou Hannah Arendt (1954/2000). E quando pretensamente há uma República das crianças ou um mundo público das crianças na escola, então o aluno se torna, decerto, público, e o professor, por outro lado, privado, isto é, torna-se este último privado de seu ensino e de sua enunciação ${ }^{3}$. Eis que o dito aluno público não é mais do que o pretenso protagonista da própria aprendizagem (protagonista que dispensaria o mestre e seu ensino); ele é, em outras palavras, o suposto sujeito autoengendrado (expressão que, na verdade, é absurda, pois um sujeito não pode se autoengendrar). De certa forma, trata-se do dito self made man; e este, por fim, não é mais do que o alegado aluno empoderado. Pois bem, quero crer que alunos empoderados em escolas desescolarizadas é o sonho de consumo do mercado neoliberal; trata-se também do sonho de consumo do poder instituído. Mas se trata, por outro lado, do pesadelo consumado daqueles que prezam a formação escolar pública. Em face disso, talvez valha a pena relembrar aqui o alerta já dado por Dufour (2005): desterritorializar a escola é fazer o jogo da economia neoliberal.

3 Faço referência aqui ao título do X Colóquio do Laboratório de Estudos e Pesquisas Psicanalíticas e Educacionais sobre a infância (Lepsi): Crianças públicas, adultos privados. 
Retomando o fio da meada, creio que seja bem razoável asseverar que a idealização da escola contemporânea decorre então do Real do declínio da polis no avançar do século XX. Entretanto, talvez se possa inferir ainda que tal idealização decorre também de uma frustração imaginária em torno da vida adulta em geral (e da vida adulta na polis em particular).

Quanto ao Real do declínio da política desde a segunda metade do século XX, ele é indissociável da ascensão da tecnoburocracia e da tecnociência ${ }^{4}$. A tecnoburocracia implica, pois, a anulação da política. E isso ocorre precisamente porque a poiesis tecnoburocrática e tecnocientífica consome a práxis política. Ou seja, as decisões políticas passam a ser tomadas primordialmente por especialistas, tecnocratas e tecnocientistas, em detrimento dos debates públicos e da persuasão política entre adultos (isto é, entre cidadãos formados). Entretanto, é preciso aqui destacar que, enquanto a política esteve libidinalmente investida na modernidade (desde pelo menos o final do século XVIII até meados do século XX), a práxis pública fez contrapeso à tecnoburocracia, ao cientificismo e até ao mercado, contrapeso esse que foi arrefecido na contemporaneidade e que, no mais, acabou conferindo a esta última um caráter monolítico, monocromático; e isso enquanto a modernidade, talvez, tenha sido mais ambivalente ou dialética (em decorrência da própria Dialética do Esclarecimento que a estruturava).

De mais a mais, uma vez que a polis declinou e a tecnoburocracia e a tecnociência ascenderam na segunda metade do século XX, não é então de surpreender que a escola contemporânea tenha sido tomada por imperativos tecnoburocráticos, tecnocientíficos e até mesmo neoliberais. Não é tampouco de surpreender que ela esteja tão imaginarizada (isto é, que ela vise o todo, a massa, a plena unidade social, como se verá melhor na sequência).

Em síntese quanto a esse ponto:

No que toca ao Real, o adulto contemporâneo inconscientemente pretende sanear o impossível da política (ainda que esta esteja declinada) por meio da educação (educação que, por óbvio, também é da ordem do impossível). E por isso, resta convocar os tecnocratas, os tecnocientistas e os impostores de plantão para supostamente sanear o impossível da educação (o que implica, assim, uma espécie de impossibilidade ao quadrado).

No que toca ao Imaginário, pode-se afirmar que quando a política passou a ser vivida no registro da impotência, a educação passou então a ser vivida no registro da onipotência. E daí, portanto, que a escola contemporânea deva pretensamente se consumar na onipotência. E ela se consuma gozando de uma pretensa inclusão do todo, de uma inclusão sem limites, sem exceções. Essa escola visa, pois, o todo das crianças, o todo dos jovens e, tendencialmente, até o todo social... desde os bebês à terceira idade. Nesse sentido, tem-se hoje uma escola amplamente desescolarizada, mas uma sociedade extremamente escolarizada! E uma sociedade escolarizada só pode ser infantilizada em função da renúncia adulta à política. Eis que estamos mesmo no tempo da criança generalizada, da criança pública.

Mas por outro lado, decorre desse gozo (de uma suposta inclusão total) que a escola deva se consumir na impotência. Afinal, para que pretensamente inclua o todo, a escola deve ser desconstruída, desescolarizada, deve se converter numa antiescola etc. Em suma: a escola deve ser consumida para melhor se consumar, e isso porque ela não poderia supostamente

4 Tal declínio, por outro lado, é indissociável dos particularismos contemporâneos. À parte o fato de haver reclamos particularistas justos, imprescindíveis e inadiáveis, seu rechaço a um modo de inscrição universal na polis só encorpa o narcisismo das pequenas diferenças. Isto é, os particularismos tornam de difícil acontecimento reconhecer um mundo público em comum ou interesses públicos válidos para todos os cidadãos da polis e não apenas para segmentos particulares. 
incluir o todo sendo tradicional ou republicana, dado que esta não visava primordialmente o todo (como se verá à frente). E disso resulta, pois, que a escola contemporânea deva se submeter à injunção superegoica de pretensamente inovar, inovar e inovar (a fím, é claro, de que o todo supostamente caiba no interior da escola).

Um ponto importante quanto à consumição da escola contemporânea é que ela é exatamente o que torna a escola incestuosa. Afinal, para consumir a escola é imprescindível:

a. horizontalizar a dita relação professor e aluno ou dessimbolizar o laço transferencial entre professor e aluno;

b. achatar o currículo;

c. afunilar o ensino e, mais ainda, a transmissão de conhecimentos públicos;

d. arrefecer a enunciação do professor (o que decerto o desautoriza e, assim, torna muito onerosa a incontrolável emergência do sujeito);

e. adequar supostamente a escola a seu público.

Isto é, é preciso centrar a escola no aluno, ou pior ainda, é preciso centrar a escola na criança e no jovem, tal como se tornou prevalente desde Maio de 1968 e desde a Contracultura, segundo Dufour (2005). Para tanto, resta, é claro, psicologizar mais do que nunca o dispositivo escolar.

Em decorrência de tal consumição, a transmissão de conhecimentos públicos na escola acabou dando lugar, contemporaneamente, ao suposto desenvolvimento de competências e habilidades pretensamente inatas e individuais. Eis, então, que a consumição incestuosa da escola contemporânea ocorre para que o adulto possa, hoje, gozar de uma pretensa consumação da escola (a dita inclusão do todo), que supostamente iria redimir as mazelas do mundo dos adultos.

Passo agora a abordar alguns traços do dispositivo escolar moderno.

Se o dispositivo escolar contemporâneo é tributário - talvez fundamentalmente - do declínio da política no avançar do século XX, já o dispositivo escolar que foi hegemônico na modernidade (no avançar do século XIX e primeiras décadas do XX) foi tributário da elevação da esfera pública a uma nova dignidade. Ele foi erigido em nome da polis, isto é, ele decorreu do investimento libidinal na Coisa Pública por parte dos cidadãos modernos. Em suma: não teria existido a escola moderna sem a polis moderna. Ou ainda: não teria existido Escola da República sem República, por óbvio.

De mais a mais, pode-se afirmar, quanto ao dispositivo escolar moderno, que ele não era totalizante nem incestuoso (isto é, nem consumado nem consumido), e isso porque a práxis política fazia contrapeso à poiesis tecnoburocrática naquele contexto histórico. E sendo assim, é sustentável a convicção de que a universalização da escola moderna diferiu da consumação da escola contemporânea (o que implica, por seu turno, que o desejo de universalização da escola moderna diferia do gozo da consumação da escola em nossos dias). Nesse sentido, a universalização da escola moderna visava todos, em vez de visar primordialmente o todo. Isto é, a universalização visava o coletivo ou a pluralidade mais do que a massa homogeneizada ${ }^{5}$. E tanto era assim que a escola moderna não gozava de uma pretensa inclusão total. Ou em outros termos, o desejo de universalização da escola era pautado por um ideal simbólico, uma

Ressalte-se que se dirige aqui uma crítica ao furor de incluir, isto é, à imaginarização hegemônica da inclusão em nossos dias. Isso não impede o reconhecimento de que há aqueles que se beneficiam da inclusão escolar. Por exemplo, as crianças e jovens com síndrome de Down dão claro testemunho desse benefício. Por outro lado, nem por isso se deve esquecer que, com certa frequência, eles também são objeto do referido furor inclusivo por parte de famílias e de escolas, o que não é de modo algum inócuo no que tange ao sujeito que os habita. 
vez que se tratava de um ideal consciente ou inconscientemente reconhecido como inalcançável (e, portanto, referido inconscientemente à castração), sendo ainda que era sob essa condição que ele balizava os esforços políticos concretos em torno da ampliação da oferta escolar na modernidade. De fato, o ideário simbólico moderno possuía sua cota de eficácia simbólica. E pode-se mostrar isso também das seguintes maneiras ${ }^{6}$ :

a. Segundo dados estatísticos referidos por Carlota Boto (2001), em 1850 a Suécia, um país reformado e pouco industrializado, possuía uma taxa de analfabetismo da ordem de $10 \%$; já a Prússia, nação mais industrializada que a Suécia, possuía $20 \%$ de analfabetismo; e a Inglaterra, país extremamente industrializado, possuía uma taxa de analfabetismo de pouco mais de $30 \%$. Ora, como se vê a partir desses dados elementares, não há relação causal (frise-se: causal) entre industrialização e baixo índice de analfabetismo (índice que, por sua vez, se encontra intimamente relacionado ao nível de escolarização de um país ou EstadoNação). Bem, se a Suécia, poucas décadas mais tarde, seria ademais o primeiro país europeu a debelar o analfabetismo (mesmo não tendo a referida nação se tornado um líder da Revolução Industrial), isso então indica que o feito educacional em questão dependeu do desejo político de universalizar a escola, ou seja, dependeu da ação política por parte dos cidadãos de uma polis, decisão que se desdobrou a partir da constituição de um EstadoNação moderno. Em outras palavras, a escolarização decorreu do projeto moderno de vida na polis mais do que dos ditos avanços do mercado à época. Ora, esse dado é, no mínimo, muito relevante quando se aborda aquilo que é designado, a partir de Lacan, como discurso do capitalista. Isto é, em tempos modernos a política fazia um justo contrapeso ao mercado. Já na modernidade-tardia não é bem assim, desafortunadamente.

b. Ainda quanto à eficácia simbólica do ideário moderno, pode-se afirmar que os países que aprofundaram sua experiência política e republicana no século XX são exatamente aqueles que hoje conseguem blindar - até certo ponto, é claro - seus sistemas escolares públicos em face da tecnoburocratização e até mesmo da consumição neoliberal. Bem, infelizmente esse não é o caso do Brasil. Por aqui, nós nos tornamos pós-modernos sem termos sido modernos. E por isso os efeitos da consumação e consumição da escola são em geral muito mais graves. Em outros termos, nossa escola é pós-moderna porque nós somos arcaicos (cf. Calligaris, 1993). Nós supostamente inovamos a escola o tempo todo justamente para que nada de fato se transforme no cenário educacional (e até mesmo no cenário político).

Ainda quanto à inclusão não toda por parte da universalização moderna, o ingresso do jovem Freud, aos 9 anos de idade, em uma escola pública vienense constituiu um exemplo significante. Como se sabe, Freud era um rapaz judeu e sem maiores recursos financeiros quando ingressou na escola, em 1865. Em Sobre a psicologia do colegial (1914/2012), o psicanalista retrata a escola pública, na qual estudou até os 17 anos; e em tal artigo Freud também afirmou, tal como é notório, que “... para muitos de nós [alunos] o caminho do saber passava inevitavelmente pelas pessoas dos professores" (p. 420). Ora, esse enunciado equivale a asseverar que nesse dispositivo escolar moderno havia ensino de conhecimentos públicos e, mais ainda, havia lugar para a enunciação do professor, isto é, para a emergência do sujeito ${ }^{7}$. Ademais, isso implicava, como não poderia ser diferente, uma inclusão não toda, afinal "Vários [alunos] se detiveram na metade desse caminho, e para alguns - por que não admitir - ele ficou bloqueado permanentemente" (Freud, 1914/2012, p. 420). Em outras palavras, a transferência, que como se sabe é a condição de possibilidade para o aprendizado,

6 Creio que o que vem a seguir se presta a debelar a crítica de que o que se propõe aqui seria um idealismo no sentido filosófico do termo.

7 Eis por que a transmissão cultural prevalecia em face do dito desenvolvimento de capacidades pretensamente naturais aos alunos. Ou em outros termos, a transmissão de conhecimentos públicos prevalecia sobre o suposto desenvolvimento de habilidades e competências inatas e individuais, o que restringia em princípio a psicologização da educação escolar. 
também impõe limites a este último, na medida em que Joãozinho aprende Geografia com o professor A, mas não necessariamente com B. Por sinal, é mesmo por conta de tais limites que, ao menos quando é possível, o corpo docente em uma escola deveria ser plural em termos de estilos de transmissão, precisamente pelo fato de tal pluralidade não elevar as vicissitudes que são inerentes à transferência no interior da cena escolar (vicissitudes essas que, afinal, são indissociáveis de uma inclusão não toda).

De mais a mais, resta ainda afirmar que se a escola moderna não era totalizante ou consumável, tampouco ela era incestuosa ou consumível. Afinal, tal dispositivo preservava a diferença de posições simbólicas e até mesmo de hierarquia entre professores e alunos. E, por isso, não se tratava de um dispositivo centrado no aluno ou muito menos na criança e no jovem. Pela mesma razão pode-se afirmar que, em princípio, o dispositivo escolar moderno não incrementava as vicissitudes que são inerentes à transmissão escolar (o que representa mais uma razão para designá-lo, portanto, como não todo e como não consumido).

Por fim, talvez seja o caso ainda de frisar que não se trata aqui de manifestar qualquer forma de nostalgia neurótica no que toca ao dispositivo escolar moderno. Afinal, nunca houve Eldorado; não há Eldorado; e tampouco haverá Eldorado. Todavia, há algo da legalidade desse dispositivo que é preciso não ignorar caso se queira tentar passar a limpo a atual educação pública em nosso país. Em outros termos, não se pode ignorar que a escola moderna não se encontrava tomada de um furor de incluir (e isso na exata medida em que se via comprometida com o ideal simbólico de universalização da educação formal). Ela também não estava tomada por um furor de sucatear-se sob o pretexto de incluir mais e melhor (empreendimento que por si mesmo só pode recair com usura em um engodo, uma vez que o autossucateamento escolar já é excludente por excelência).

Outro aspecto relevante a partir do que foi destacado aqui é que enquanto houve Escola da República não houve República das crianças na escola (isto é, os alunos não eram públicos, posto que seus professores não se encontravam privados de ensino e de enunciação). E isso equivale a afirmar, decerto, que a escola moderna, no final das contas, não visava propriamente salvar o mundo, mas sim introduzir as crianças e os jovens no mundo (introdução que serve de condição para que estes processualmente mudem sua posição discursiva: de cidadãos em formação para cidadãos formados $)^{8}$.

Enfim, o que essa reflexão sobre os dispositivos escolares talvez no lembre é, sobretudo, que a dignidade da escola somente será reconhecida na proporção de sua desidealização. Todavia, que a escola não rode assim tão bem - não por impotência, mas por impossibilidade -, é tudo aquilo de que, na contemporaneidade, nada se quer saber no que toca à educação. Daí, é claro, a hegemonia da miséria neurótica por meio da qual a escola contemporânea é consumida para, supostamente, melhor se consumar.

8 Por óbvio, a política também não salva o mundo. Mas é no âmbito político, a despeito do declínio da esfera pública na contemporaneidade, que se pode imprimir um pouco mais de durabilidade ao mundo (o qual, é importante frisar, se encontra sempre rente à destruição). Vale lembrar ademais que, em termos estruturais, a política nada mais é do que a reinvenção da aliança fraterna, aliança que se seguiu ao mítico assassinato do protopai da horda primitiva e que se constituiu a partir da interdição ao incesto autoimposta por esses filhos bastardos, os quais se tornaram, assim, irmãos no interior de uma aliança política. 


\section{Referências}

Arendt, H. (2000). Entre o passado e o futuro (M. W. Barbosa, trad.). São Paulo, SP: Perspectiva. (Trabalho original publicado em 1954)

Boto, C. (2001). A moderna escola do Estado-Nação: templo da República e da cidadania. Revista Mackenzie de Educação, Arte e História da Cultura, 1(1), 55-64.

Calligaris, C. (1993). À escuta do sintoma social. Anuário Brasileiro de Psicanálise, 1(1), 11-22.

Costin, C. (2017, 20 de novembro). Educação e eleições formando cidadãos competentes para o século 21. Folha de S.Paulo. Recuperado de https://bit.ly/2Y4Jtxq

Dufour, D. R. (2005). A arte de reduzir as cabeças: sobre a nova servidão na sociedade ultraliberal (S. F. Felgueiras, trad.). Rio de Janeiro, RJ: Companhia de Freud.

Freud, S. (2012). Sobre a psicologia do colegial. In S. Freud, Obras Completas (Paulo César de Souza, trad., vol. 11, pp. 418-423). São Paulo, SP: Companhia das Letras. (Trabalho original publicado em 1914).

Lefort, C. (1999). Formação e autoridade: a educação humanista. In C. Lefort, Desafios da escrita política (E. M. Souza, trad., pp. 207-224). São Paulo, SP: Discursos.

Recebido em novembro/2018 - Aceito em fevereiro/2019. 